\title{
Influence of pesticides on respiratory pathology - a literature review
}

\author{
Simina Tarmure ${ }^{1, A, D \oplus}$, Teodora Gabriela Alexescu ${ }^{1, A, F \oplus}$, Olga Orasan $^{1, C-D \oplus}$, Vasile Negrean ${ }^{1, E \oplus}$, \\ Adela Viviana Sitar-Taut ${ }^{1, C \oplus}$, Sorina Cezara Coste ${ }^{1, C \oplus}$, Doina Adina Todea ${ }^{2, A, F} \oplus$ \\ ${ }^{1}$ Department of Internal Medicine, 'Iuliu Hatieganu' University of Medicine and Pharmacy Cluj-Napoca, Cluj-Napoca, \\ Romania \\ ${ }^{2}$ Department of Pneumology, 'luliu Hatieganu' University of Medicine and Pharmacy Cluj-Napoca, Cluj-Napoca, \\ Romania \\ A - Research concept and design, B - Collection and/or assembly of data, C - Data analysis and interpretation, \\ $D$ - Writing the article, E-Critical revision of the article, F - Final approval of article
}

Tarmure S, Alexescu TG, Orasan O, Negrean V, Sitar-Taut AV, Coste SC, Todea DA. Influence of pesticides on respiratory pathology - a literature review. Ann Agric Environ Med. 2020; 27(2): 194-200. doi: 10.26444/aaem/121899

\section{Abstract}

Introduction. Pesticides are widely employed in agriculture, and the food industry is forced to combat the pests and diseases they cause. Respiratory pathology is related to occupational exposure to pesticides. Impairment of pulmonary function was observed among people professionally exposed to pesticides. Because of the marked use of pesticides in agriculture during the last 20 years, there has been a significant increase in respiratory problems within the population, not only among people who come in direct contact with them, but even in the case of manipulators.

Objective. The aim is a review of the literature of the past 10 years on the correlation between occupational exposure to pesticides and respiratory pathology.

Materials and method. Electronic search in 'Pub Med' and 'Web of Science' was performed in September 2019 to find papers regarding the above-investigated aspects. Abstracts and full-text articles containing the targeted subject were included. Reviews and studies about the influence of pesticides on other pathologies than respiratory were excluded. After applying the inclusion and exclusion criteria, eligible full-text articles were identified.

Conclusions. Exposure to pesticides is highly correlated with respiratory pathologies (asthma, COPD, lung cancer). Contact with these substances can occur at any time in the production, transport, preparation or application of the treatments. Numerous studies documented the association between exposure to pesticides, and therefore the increased incidence of respiratory, cardiovascular and renal diseases, as well as the aging phenomenon.

\section{Key words}

pesticides, respiratory pathologies, manipulators|

\section{Abbreviations}

2,4, D - Dichlorophenoxyacetic acid; 2,4,5; T - Trichlorophenoxyacetic acid; COPD - Chronic Obstructive Pulmonary Disease; DNA - Deoxyrbonucleic acid; DDT - Dichlor-Diphenyl-Trichlorethan; DDD - Dichlor-Diphenyl-Dichlorethane; DNA - Deoxyribonucleic acid; HCB - Hexachlorobenzen; FVC - Forced Vital Capacity; FEV - Forced Expired Volume per 1 second; FEF $\mathbf{2 5 \%}$ - 75\% - Forced Expiratory Flow between 25\% - 75\% of forced vital capacity; MCPA - 2-Methyl-4Chlorophenoxyacetic acid; NADPH - Nicotinamide Adenine Dinucleotide Phosphate; NOX - Nitrogen Oxides; PEFR - Peak Expiratory Flow Rate.

\section{INTRODUCTION}

Phytosanitary substances or pesticides are widely used to combat pests in such sectors as agriculture, fisheries and forestry. The chemical structure of these substances includes the presence of mercury, sulfur, phosphorus, arsenic, hydrocarbons, nitrates and nitro derivatives, all of which are highly toxic to the human organism. They have different trade names and are presented in various forms: solutions, paste and, granules [1]. There is suggestive evidence for a link between occupational exposure to pesticides and chronic bronchitis, respectively, COPD. Apart from professional

Address for correspondence: Teodora Gabriela Alexescu, Department of Internal Medicine, 'Iuliu Hatieganu' University of Medicine and Pharmacy, Cluj-Napoca, Romania.

E-mail: teodora.alexescu@gmail.com

Received: 24.02.2020; accepted: 28.04.2020; first published: 08.05.2020 exposure to pesticides, the general population may also be exposed due to residuals in the environment (outdoor or indoor air, water and food). The degree of exposure is dependent on the persistence of residues, the use of pesticides inside or outside the house, in gardens, on pets or animals, as well as the distance of residences from areas treated professionally with these substances.

Classification of pesticides. Pesticides used to combat animal diseases and pests are called plant protection substances, and those used to control weeds are called herbicides [2]. Tables 1 and 2 show the classification of pesticides according to several criteria, as accepted in the professional field. 
Table 1. Classification of pesticides [2]

\begin{tabular}{|c|c|}
\hline Classification criterion & Classification \\
\hline $\begin{array}{l}\text { Group of organisms } \\
\text { fought against }\end{array}$ & $\begin{array}{l}\text { a. virulicidal (virulostatic); } \\
\text { b. bactericidal (bacteriostatic); } \\
\text { c. fungicides or anticryptogarnic: } \\
\text { d. mixed action (fungicide + zoocide); } \\
\text { e. chemotropic insecticides (repellents, attractants); } \\
\text { f. acaricides; } \\
\text { g. nematocides and soil sterilizers; } \\
\text { h. rodenticides; } \\
\text { i. molluscids (c-j-au classes, zoocidal action); } \\
\text { j. herbicides. }\end{array}$ \\
\hline Mode of action & $\begin{array}{l}\text { a. contact (touch); } \\
\text { b. ingestion (stomach) } \\
\text { o. asphyxiant (fumigants) } \\
\text { d. penetrating; } \\
\text { e. combined; } \\
\text { f. systematic. }\end{array}$ \\
\hline Chemical nature & $\begin{array}{l}\text { a. inorganic or mineral; } \\
\text { b. organic, synthesis; } \\
\text { c. practical organic; } \\
\text { d. organo-mineral; } \\
\text { e. biological; }\end{array}$ \\
\hline Physical state & $\begin{array}{l}\text { a. Solid: powders for soil or seed dredging; wettable } \\
\text { powders, soluble powders; granules } \\
\text { b. paste } \\
\text { c. volatile or non-volatile liquids; } \\
\text { d. gaseous. }\end{array}$ \\
\hline Toxicity & $\begin{array}{l}\text { a. Extremely toxic; } \\
\text { b. strongly toxic; } \\
\text { c. moderately toxic; } \\
\text { d. low toxicity; } \\
\text { e. practically non-toxic; } \\
\text { f. harmless }\end{array}$ \\
\hline
\end{tabular}

Table 2. Categories of commonly used pesticides

\begin{tabular}{ll}
\hline Type of Pesticide & Chemicals \\
\hline Insecticide & $\begin{array}{l}\text { Organochlorines (DDT, DDD, dicofol),), pyrethroids } \\
\text { (pyrethrins, permethrin, deltamethrin, cypermethrin), } \\
\text { organophosphates (chlorpyrifos, diazinon, parathion, } \\
\text { malathionchlorinated cyclohexanes } \\
\text { and benzenes (lindane, HCB), carbamates (aldicarb, } \\
\text { aminocarb), cyclodienes (aldrin, endosulfan, chlordane } \\
\text { and toxaphene), chlordecone (mirex),, rotenone, Bacillus } \\
\text { thuringiensis (protein product) }\end{array}$ \\
\hline Herbicide & $\begin{array}{l}\text { Amide (propanil), urea derivatives, Chlorophenoxyl (2,4-D, } \\
\text { 2,4,5-T and MCPA), triazines (atrazine), glyphosate, bipyridils } \\
\text { (paraquat and diquat) }\end{array}$ \\
\hline Bactericide & $\begin{array}{l}\text { Chlorine-releasing agents, dichloronitrobenzene, chlorine, } \\
\text { triazine-S-triones }\end{array}$ \\
\hline Fungicide & $\begin{array}{l}\text { Captan, captofol, dithiocarbamate, pentachlorophenol, } \\
\text { iprodione, sulphur }\end{array}$ \\
\hline Rodenticide & $\begin{array}{l}\text { Coumadin and derivatives, sodium } \\
\text { fluoroacetate, strychnine, anticoagulants }\end{array}$ \\
\hline Fumigante & Methylbromide, aluminum/zinc phosphide, sulfur \\
\hline
\end{tabular}

\section{OBJECTIVE}

Long-term contact with pesticides interferes with the function of various devices and systems: the central nervous system, respiratory system, renal system, cardiovascular system, and the endocrine system $[3,4]$. There are numerous communications regarding workers' exposure to pesticides, but few of them are aimed at investigating the role of pesticides in respiratory pathology in other areas of work, such as manipulators and pesticide carriers. The presented study sums up the conclusions of studies that have also targeted less researched areas on the chosen topic, such as the practical pathology that can occur not just farmers, but also in transporters and pesticide manipulators,. The incidence of pesticide use in triggering respiratory diseases was the measure of the end result of this study, the outcome of which was the incidence of using pesticides on respiratory pathology.

Generalities concerning the involvement of pesticides in health - pesticide exposure. Achieving protection against pests with pesticides involves multiple actions: seed treatment, soil treatment, fumigation, spraying, etc. Contact with these substances can occur at any time in their production, transport, preparation or application of the treatments. The use of pesticides involves several steps: - preparing substances with the necessary mixtures is the stage where the risk of intoxication is increased, as concentrated substances are handled;

- spreading the pesticide on crops or areas to be sanitized;

- cleaning tools and machines used in the treatment process.

Seed treatment is usually carried out in closed spaces (silos) which leads to a working atmosphere heavily loaded with pesticide particles. The harvesting, packaging and transport of the products are also not free from the risk of intoxication. [3] The factors involved in the occupational exposure to pesticides usually include the intensity of application, frequency, duration and method, safety measures (e.g. use of personal protective equipment), as well as the physico-chemical and toxicological characteristics of the used pesticides.

People and groups at risk. This includes pesticidemanipulating workers - from pesticide preparation to pesticide spreading, workers responsible for cleaning pesticide handling systems, as well asthose near the premises where disinfection procedures are carried out [3].

Pesticide poisoning. The penetration of phytosanitary substances into the human body can occur by accidental ingestion, vapour inhalation, or direct contact with the skin: - inhalation poisoning is an important way, as the pesticide reaches the body in the form of aerosols, vapours, dust or mist;

- contact with the skin or eyes is the most common way of exposure when using sprays. Formulas containing solvents or surfactants, atmospheric humidity and high temperature increase absorption in the skin;

- ingestion is the rarest route of intoxication, usually by accident in the case of children, or in the case of smoking and food consumption during pesticide handling [3].

Pesticides are absorbed by the target organisms, specifically those to which they have to validate their action (insects, mites, worms) and can disperse in the environment. The adverse effects of pesticides depend primarily, but not only on their properties (mode of action, retention capacity, physical presentation state, degree of toxicity) [2], but also on the soil and agricultural characteristics. These adverse effects are closely correlated with the ability of pesticides to persist in the environment and to bio-accumulate [4]. 
Respiratory effects of pesticides. Respiratory diseases represent a major health problem for agricultural workers. An increased onset of respiratory manifestations is associated with the exposure to pesticides. Recent studies have identified a number of respiratory symptoms associated with occupational exposure to pesticides [5]. Respiratory pathologies among people exposed to pesticides and the the association between bronchial asthma and occupational exposure to pesticides have been well documented, mostly in agricultural occupations [6].

Mechanism of pesticide action on the respiratory system. Respiratory exposure usually occurs when highly volatile pesticide products are applied, especially for those who work without respiratory protective equipment (filter mask) or in a low-ventilation environment. In agricultural occupations, respiratory pesticide exposure accounts for about $10 \%$ of cases [5]. Respiratory exposure may occur in the area where the disinfection was practiced by the inhalation of aerosols or particulates contaminated with pesticides from dusty areas, such as the uneven roofs of treated buildings, or enclosed spaces with weaker air circulation [3].

\section{PESTICIDE INDUCED RESPIRATORY PATHOLOGY}

Bronchial asthma - pathogenetic mechanisms in pesticideinduced asthma. Many pesticides are able to directly alter the bronchial lining through irritation, inflammation, immunosuppression, increasing susceptibility to allergens or other stimuli. Of these, organophosphorus pesticides are associated with an increased incidence of asthma $[7,8]$.This class of pesticides presents:

- effects on cholinesterase enzymes function with disruption of normal cellular metabolism of proteins, carbohydrates and fats [9], and genotoxic effects (DNA structure damage and cellular apoptosis) [10]. OPs act by inhibiting acetylcholinesterase which hydrolyzes the neurotransmitter acetylcholine. Acetylcholinesterase inhibition increases acetylcholine quantity and persistence on nicotinic and muscarinic receptors in target tissues, leading to cholinergic over-expression, and the cholinergic over-epression of muscarinic receptors M3 on the smooth muscle of the airways leads to broncho-constriction [11]. Another mechanism by which OP intervenes in the induction of bronchial asthma by hyper-reactivity in the respiratory tract, is the blocking of the M2 selfinhibiting muscarinic receptors. These are located in the parasympathetic nerves, responsible for the innervation of the smooth muscle of the airways [11];

- effects on cellular metabolism inducing cellular oxidative stress via mitochondrial function disorder [12].

An organophosphate pesticide, called Chlorpyrifos is used on crops, animals and buildings or other places in order to annihilate pests, insects and worms. It has been shown to have the ability to significantly boost vagal induced airway resistance and the elasticity of tissue [7]. Hernandez et al drew attention to experimental studies suggesting a potential link between respiratory hyper-responsiveness induced in allergic asthma and exposure to pesticides. According to the authors, this can also be explained by the increase of surface antigen expression of T lymphocytes [7]. The use of pesticides is associated with an increased risk of asthma, and may also exacerbate a previous asthma condition, or even act as a trigger for asthma attacks by increasing bronchial hypersensitivity. A study of the West Virginia -SUA National Institute of Occupational Safety and Occupational Health, Department of Respiratory Disease Studies [9], showed an exacerbation of symptoms for pesticide applicators in agriculture, known for asthma, after pesticide handling (exacerbation of asthma defined as at least one emergency visit for an episode of wheezing in the last 12 months). The surveyed workers had used 36 specific pesticides in the previous 12 months and conducted various agricultural activities $-22 \%$ of the 926 workers suffered asthma exacerbations from pesticide use [9].

The majority of pesticides, are small molecules $(0.001 \mu \mathrm{m})$ which can exacerbate the symptoms of atopic patients, the symptoms of asthma and contact dermatitis by forming haptens. In addition to type I and IV hypersensitivity, the development of respiratory disturbances can be attributed to an oxidative stress reaction. Oxidative stress results from an imbalance in the oxidation/anti-oxidation processes in favour of oxidants, causing biological changes that are involved in many pathological conditions, including respiratory diseases. Oxidative stress can result in pulmonary damage by acting on the cellular or extra-cellular redox status, irreversible oxidative changes in protein or DNA structures, mitochondrial dysfunction and alteration of the expression and activity of NOX enzymes (NADPH - nicotinamide adenine dinucleotide phosphate oxidase), and the antioxidant enzyme systems. Acute and chronic lung disorders are usually associated with increased oxidative stress [13]. Oxidative stress is implicated in many of the pathogenic processes that underlie COPD, such as direct tissue destruction, blocking the mechanism of antiproteases, promoting mucus hypersecretion, alteration of the vascular barrier function, resulting in bronchial wall edema, bronchoconstriction and inflammation [13]. Pesticides that can cause laryngeal and bronchial spasm are predominantly organo-phosphorus and carbamates that have anticolinesterase activity and are known to cause asthma episodes. Organophosphates and $\mathrm{N}$-methyl carbamates inhibit cholinesterase activity, resulting in the accumulation of acetylcholine in the nervous system. Decreased cholinesterase activity $-60 \%$ of the baseline, may produce symptoms such as vertigo, anxiety, nausea, vomiting, diarrhea, wheezing, bronchospasm, difficulty in breathing, hypersexorption and miosis. Severe poisoning results in a greater depression of cholinesterase activity and may lead to loss of consciousness, pulmonary oedema, respiratory failure and ultimately, death [14]. Pyrethroid derivatives are also allergenic, causing asthma-like respiratory episodes, even in subjects with no disease prior to exposure.

Chronic obstructive pulmonary disease. There is also well-documented evidence regarding the correlation of occupational exposure to pesticides and chronic bronchitis, respectively, COPD. Yeah, et al. [15]. found a correlation between occupational exposure to pesticides and chronic bronchitis, where there occurred a significant exposureresponse relationship between exposure to fungicides and the production of sputum and wheezing. Another study on workers in the Polish pesticide industry showed that an increased prevalence of COPD (19.3\% vs. $3 \%$; $p=0.002)$ was correlated with pesticide exposure at work [16]. Episodes of acute pesticide poisoning can contribute more to obstructive 
pulmonary disease than the exposure to low levels in the long-term. An agricultural health study on farmers who raise animals and use specific pesticides also showed a positive link between exposure to pesticides and chronic bronchitis. The study involved 22,491 farmers involved in animal production activities and using specific insecticides (organophosphates, carbaryl, lindane, permethrin). Exposure to pesticides was associated with diagnosed chronic bronchitis (OR:1.59; 95\% CI:1.16, 2.18), or to chronic bronchitis symptoms, i.e. cough and phlegm for at least 3 months in 2 consecutive years (OR: 1.69; 95\% CI: 1.42, 2.01) [17].

Hoppin et al. [18] showed that 11 pesticides, among them organochlorinated pesticides (heptachlor-clordan, DDT, lindane and toxafen), organophosphorus pesticides (coumaphos, diazinon, dichlorvos, malathion, parathion, carbofuran), herbicides permethrin, chlorophenoxy (2,4,5-T and 2,4,5-TP), as well as herbicides such as chlorimuron-ethyl and petroleum oil, present a significant correlation with chronic bronchitis in people with high pesticide exposure (OR:1.85, 95\%, CI: 1.51,2.25) and pesticides off-farm (OR:1.40, 95\% CI:1.04,1.88) [18].

Lung cancer. Occupational exposure to pesticides has also been identified in the development of lung cancer, especially in the agricultural environment. A 20-year study on pest control workers in Florida, USA, suggested that longer-term occupational exposure of more than 18 months to organophosphates, carbamate and herbicides with phenyloxiacetic acid, was associated with a higher mortality rate through lung cancer [19]. Chlorpyrifos [20], diazinon [21], metolachlor [22], pendimethalin [23, 24], dieldrin organochloride $[25,26]$ and carbofuran carbamate $[26,27]$ have been extensively studied in terms of correlation with the risk of developing lung cancer.

\section{RESULTS}

In the study by Lee W.J. et al. [20] the ratio of identified cancer cases - patients exposed to chlorpyrifos vs. unexposed patients - was OR: 0.97, 95\% CI:0.87-1.08. The incidence of lung cancer was positively associated with both the total number of days of simple exposure to chlorpyrifos and the total number of days of intense exposure to chlorpyrifos (OR:1.80, 95\% CI: 1.00-3.23). After statistical adjustments of the data studied in terms of pesticide and demographic exposure indices, patients who had prolonged exposure to chlorpyrifos (more than 56 days), a relative risk of developing lung cancer was identified, 2.18 times higher than patients who were not exposed to chlorpyrifos (OR:2.18, 95\% CI:1.31-3.64). Exposure to 2 widely-used types of insecticides, chlorpyrifos and diazinon, was statistically correlated with an increased incidence of lung cancer. In the case of chlorpyrifos, the odds ratio (OR) identified $\mathrm{OR}=1$ at odds of $1.1,1.7,1.9$ and $\mathrm{P}$-trend $=0.03$, and in the case of diazinon $\mathrm{OR}=1$ at odds of 1.6, 2.7, 3.7 , and P-trend $=0.04$, demonstrating a strong correlation between the incidence of lung cancers and exposure to both types of insecticide [20,21].

The incidence of lung cancer among farmers and nursery workers exposed to Metolachlor (a herbicide from the chloracetanilide family) has been shown to be elevated, both in normal exposure to this type of insecticide (rate ratio (RR):1.91, 95\%, CI: 0.79-4.48) and at intense insecticide exposure (RR:1.37, 95\%, CI: 0.51-3.72) [22]. In a study on 9,089 farmers exposed to Pendimethalin, there was some evidence of an increased risk of lung cancer, but only in subjects with the highest exposure to pendimethalin [23].

Organochlorine insecticides are a class of pesticides very common in agriculture forto combatting pests. Previous evidence that they have a negative effect on estrogen has led to the hypothesis that organochlorine insecticides can contribute to hormonal mediated tumours. Studies on laboratory animals have been conclusive, and epidemiological studies have shown that organochlorine insecticides are determinants in the occurrence of various cancers, such as sarcomas, non-Hodgkin's lymphoma, leukemias, and localizations in the prostate, lung, pancreas and breast cancer [25]. Lung cancer was identified as having a 3-fold incidence in subjects exposed to more than 109 total days of carbofuran, one of the most toxic carbamate pesticides, the statistical significance being demonstrated by a Rate Ratio (RR) of 3.0, compared to patients who have been exposed to this insecticide for a total of less than 9 days [26]. Intensive exposure to dicamba (a chlorinated derivative of anisic acid used as a broad spectrum herbicide) resulted in a relative increase in lung cancer incidence, compared to low exposure to dicamba, but the growth is absolute compared to patients not exposed to this type of insecticide. The result is statistically significant $-\mathrm{OR}=1.6,95 \%, \mathrm{CI}: 0.7-3.4$ [27]. However, there are also several studies showing statistically weak or a lack of correlation between the occupational use of pesticides and lung cancer, for example, Rusiecki et al. [22], Freeman et al. [21], Christensen et al. [28], van Bemmel et al. [29], Lynch et al. [30], Lynch et al. [31], Mahajan et al. [32; 33], Koutros et al. [34] and Greenburg et al. [35] (Fig. 1).

Weak associations with lung cancer were shown by exposure to malathion, atrazine, coumaphos, S-ethyl-N, $\mathrm{N}$-dipropylthiocarbamate, alachlor, trifluralin and chlorothalonil. Lack of association with lung cancer was shown by exposure to butylate, cyanazine, phonophos, phorate, glyphosate, dichlorvos, captan and permethrin.

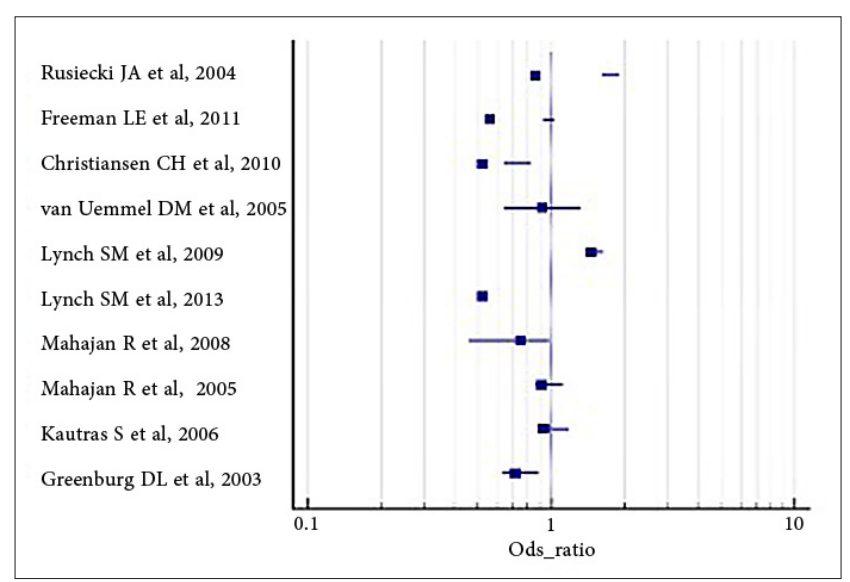

Figure 1. Lung cancer and exposure to pesticides

More recent studies add chlorophenol-related compounds to the list of pesticides representing risk factors for lung cancer. Chlorophenols and related phenoxyacetic acids are pesticide groups with high toxicity during their production. Chronic exposure to PAs and CPs in pesticide production workplaces was strongly reported to be associated with the lung cancer in a meta-analysis by by Zendehdel $\mathrm{R}$ et al. [36]. 
Other respiratory manifestations associated with exposure to pesticides. Deterioration of lung function is associated with exposure to organophosphorus and carbamate insecticides, substances known to be major inhibitors of cholinesterase - the enzyme catalysing the decomposition of acetylcholine and other choline esters that function as neurotransmitters. Acetylcholine is the mediator of the parasympathetic nervous system and acts on 2 types of receptors: muscarinic and nicotinic. Of the muscarinic receptors, the muscarinic $\mathrm{M} 3$ receptor, which is found in smooth muscles, blood vessels and lungs, is responsible for vasoconstriction and bronchoconstriction. There are 2 types of cholinesterases in the human body: acetylcholinesterase, found in erythrocytes, lungs, spleen, grey matter of the nervous system, and pseudocolinesterase, which is present in the serum as well as in the pancreas, heart, liver, muscle and white matter of the central nervous system.

Several studies performed on guinea-pigs exposed to organophosphorus insecticides have demonstrated increased pro-inflammatory cytokine production. The cytokines, protein-like molecules that control immune responses, intervene in the mechanisms of inflammation, in antiinfectious and antitumour defence. At the pulmonary level, they can mediate responses to tissue damage, eliminating injury, repairing lung tissue, and returning to the physiological homeostasis of the body. When this response is exaggerated and/or cytokine production is impaired, chronic, repetitive inflammatory reactions may occur, leading to respiratory remodeling, excessive extracellular matrix accumulation and pulmonary fibrosis [37]. A number of over 50 types of cytokines have been described as having a role in the mechanisms of asthma and COPD development [37]. Occupational exposure to even low levels of organophosphorus pesticides could lead to restrictive lung dysfunctions [38].

Among the most commonly encountered respiratory manifestations related to professional exposure to pesticides were dyspnea, coughing and expectoration. The prevalence of cough, nasal congestion, nasal irritation, and chest constriction is significantly higher in agricultural workers exposed to anticolinesterase pesticides, compared to controls [39]. The same observation was identified in a study on agricultural workers by Ohayo-Mitoko et al. [14] who reported that acetylcholinesterase inhibitors, including dimethoate, malathion, benomyi, mancozeb, metomyia, aldicarb and propineb, are associated with an increased prevalence of respiratory manifestations, such as cough, rhinorrhea, wheezing, chest pain, shortness of breath and pharynx irritation.

Occupational exposures to fumigants - substances used in smoking operations to kill parasites in orchards and vines, such as methyl bromide, can also cause such respiratory symptoms as dyspnea, cough, respiratory irritation and oedema pulmonary lesions. These respiratory manifestations are often accompanied by other local or systemic symptoms, such as fatigue, headache, dizziness, vomiting, abdominal pain, tremor, seizures, paraesthesia, ataxia and impairment of the function of other organs [40]. People who live in the proximity of fumigants (the most toxic pesticides used in agriculture) experience more frequent laryngeal irritation, headache, coughing, rhinitis, dyspnea, wheezing [41]. In a comparative case study on agricultural workers in India, quoted by Ye et a., the exposures to organophosphorus and carbamate were significantly associated with the reduction of the following parameters: FVC, $\mathrm{FEV}_{1}$, ratio $\mathrm{FEV}_{1} / \mathrm{FVC}$, FEF25\% $-75 \%$ and PEFR. In this study both obstructive and restrictive anomalies were reported in association with occupational exposure to pesticides [40].

Newman et al. reported that occupational exposure to insecticides was associated with an increased risk of sarcoidosis in a case control study on 706 subjects. The patients, from 10 medical centres, had been newly diagnosed with sarcoidosis. The investigators' questionnaire also referred to professional or non-professional exposure to pesticides. The authors noted a positive association between sarcoid and professions involving pesticide exposure [42]. Exposure to organophosphate insecticides can increase the risk of alergic rhinitis and the exposure to glyphosate herbicides and petroleum oil may favour the recurrence of rhinitis episodes [43]. Of the organophosphoric substances, only 4 (chlorpyrifos, diazinon, dichlorvos and malathion), together with carbaryl and the use of permethrin in animals, have been shown to be predictors of allergic rhinitis, according to the above authors, in another study among farmers applying pesticides [43].

Pesticides should not be omitted from the risk factors for farmer's lung - a typical type of hypersensitivity pneumonitis, which is well-known for respiratory morbidity among farmers. Dichlorodiphenyl trichloroethane, lindane and aldicarb have been independently associated with farmer's lung. Organochlorine pesticides and carbamate can also be considered potential risk factors for farmer's lung [44].

\section{Respiratory disorders through exposure to pesticides in non-agricultural areas.}

An original study by Jalilian $\mathrm{H}$ et al. [45] on the exposure to the effects of pesticides in another professional sector pesticide traders. Manipulation of pesticide mixtures has proved a relationship with an increased prevalence of dermal and respiratory symptoms, as well as increased biomarker concentrations of oxidative stress. The authors of the study found that the prevalence of wheezing, chest constriction, chronic cough and mucus hypersecretion was significantly higher than in the control group. In parallel, they found that those traders did not use protective equipment, which may partly explain the results of the study. [45] Kesavachandran C., according to Lekei E. E. [46], found that respiratory distress occurred 8 times more frequently in pesticide retailers compared to the general population. The significant increase observed in the prevalence of respiratory symptoms among the retailers seems to be explained by the manipulation of organophosphorus compounds - one of the most widely-used pesticide categories. They also reported that the owners of the pesticide stores had a significant reduction in spirometric indice, as shown by the results: low $\mathrm{FEV}_{1}$ was observed in 10 exposed subjects compared to 6 controls; low PEFR was observed in 3 exposed subjects compared to 2 control subjects; low FVC was observed in 5 shopkeepers compared to 3 controls. Mean value of PEFR (L/min) was significantly low in exposure $(330 \pm 183.08)$ compared to control (457.14 \pm 100.91 ); mean values of FVC (L) and $\mathrm{FEV}_{1}(\mathrm{~L})$ were 2.53 \pm 0.32 and $2.57 \pm 0.71$, respectively, compared to controls (FVC: $2.84 \pm 0.81$ and $\mathrm{FEV}_{1}: 2.04 \pm 0.58$ ); mean $\mathrm{FEV}_{1}$ was significantly low in controls compared to exposed subjects.

Another interesting but less evaluated aspect are the seasonal variations of respiratory effects from exposure to pesticides. A study carried out by a team of Brazilian 
researchers [47] tracked the respiratory consequences of exposure to pesticides among rural workers and their relatives during the harvest season and also out-of-season. Participants in the study were people professionally and environmentally exposed to multiple pesticides since childhood. During the harvest season and off-season, they showed a $40 \%$ prevalence in the agricultural season and $30.7 \%$, respectively, in the off-season for coughing, $30.7 \%$ and $24 \%$, respectively, for allergic rhinitis, and $24 \%$, respectively, $17.3 \%$ for chest tightness. Significant correlations between changes of spirometry indexes and exposure levels were found both during harvest and off-season. Moreover, they found significant associations between short- and long-term exposure to pesticides, as well as a decrease in pulmonary function parameters in both the harvest season and offseason. These findings provide additional evidence for the adverse effects of pesticide exposure on respiratory health, and the risk of developing a chronic lung pathology. At the same time, a Brazilian team found that farmers' families are often exposed to pesticides either by locating near planting sites, by using or storing pesticides at home, or by contacting contaminated clothing and work tools of family members. This residential contact may be an additional exposure that increases the risk and effects on human health [47].

In Romania, research was carried out between 2003 - 2013 on a rural population in an area defined as a small family farm [4]. The study showed that the among the acute diseases caused by the pesticides, the prime diseases were those of upper and lower airways. Among the chronic respiratory diseases in this population with exposure to pesticides, bronchial asthma ranked in first place, with an oscillating evolution of incidence during the time of the study, while COPD showed a markedly decreasing trend, with the number of new cases being less than $1 \%$ [4].

The quarterly evolution of adult asthma frequency has shown a seasonal character, with increased incidence in spring when pest control procedures are carried out, but without the possibility of eliminating the allergic etiology of the disease. Statistical analysis showed that in workers who have handled pesticides without protective equipment, there was a big difference between the actual age of the workers and the estimated spirometry, i.e. pulmonary age, as opposed to the group who used protective equipment, or of those who were not exposed, where the difference between real and pulmonary age was at the statistically or statistically significant limit of significance [4].

\section{CONCLUSIONS}

With a population growth from about 6 billion within the early 2000 s to over 7 billion, it has now become imperative to extend agricultural production to provide adequate supplies of food. Protecting crops throughthe widespread use of pesticides may be a natural process and current practice, but it has an impact on the environment and implicitly on the health of the population. Exposure to pesticides is correlated with various respiratory pathologies - asthma, COPD and lung cancer, as well as with various respiratory manifestations - cough, wheezing and dyspnea. Pesticides which can cause laryngeal and bronchial spasm are predominantly organophosphorus and carbamates, that have anti-colinesterase activity and are known to cause asthma episodes. Together with pulmonary cancer, bronchial asthma and COPD, other respiratory diseases like sarcoidosis, farmer's lung and allergic rhinitis were also associated with occupational exposure to pesticides. Research results from current studies on non-occupational exposure to pesticides and their impact on health in the general population should also not be omitted. Knowing and recognizing these respiratory health problems of farmers and their families, and also of manipulators, are essential for early diagnosis, appropriate treatment, and preventive measures.

\section{Conflict of Interests}

The author does not have any financial interest involving the companies and materials mentioned in this study.

\section{REFERENCES}

1. Banu E. Prevenirea intoxicatiilor cu pesticide in activitatile din agricultura. Ministerul Muncii, Solidaritatii Sociale si Familiei, Inspectia Muncii. www.itmvaslui.ro/prevenirea\%20intoxicatiilor\%20 cu\%20pesticide.doc (access:2020.02.20)

2. WHO. The who recommended classification of pesticides by hazard and guidelines to classification 2009. https://conspecte.com/Agricultura/ pesticidele.html (access: 2020.02.20)

3. Poisons Control, Department of Health and Community Services. Guidelines for the safe use of pesticides in non-agricultural workplaces. https://ww2.health.wa.gov.au/ /media/Files/Corporate/general\%20 documents/pesticides\%20and\%20chemicals/PDF/Guidelines_safe_ use_pesticides_non-ag.pdf (accessed: 2019.06.24)

4. Havrila (Lovasz) M E. Particularitati ale utilizarii si expunerii la pesticide in mediul rural.file://C:/Users/simin/Downloads/ Dana\%20MOLDOVAN_rezumatteza_de_doctorat_ro_ lovaszmariaelisabeta_2014-06-19_13_15_51.pdf (access:2019.06.20)

5. Mamane A, Baldi I, Tessier JF, Raherison C, Bouvier G. Occupational exposure to pesticides and respiratory health. Eur Respir Rev. 2015; 24(136): 306-19.

6. Ye M, Beach J, Martin JW, Senthilselvan A. Pesticide exposures and respiratory health in general population. J Environ Sci (China). 2017; 51: 361-370.

7. Hernández AF, Parrón T, Alarcón R. Pesticides and asthma. Curr Opin Allergy Clin Immunol. 2011; 11: 90-96. doi: 10.1097/ ACI.0b013e3283445939

8. Nicolopoulou-Stamati P, Maipas S, Kotampasi C, Stamatis P, Hens L. Chemical Pesticides and Human Health: The Urgent Need for a New Concept in Agriculture. Front Public Health. 2016; 4: 148.

9. Henneberger PK, Liang X, London SJ, Umbach DM, Sandler DP, Hoppin JA. Exacerbation of symptoms in agricultural pesticide applicators with asthma. Int Arch Occup Environ Health. 2014; 87(4): 423-32.

10. Li D, Huang Q, Lu M, Zhang L, Yang Z, Zong M, Tao L. The organophosphate insecticide chlorpyrifos confers its genotoxic effects by inducing DNA damage and cell apoptosis. Chemosphere. 2015; 135: 387-93.

11. Shaffo FC, Grodzki AC, Fryer AD, Lein PJ. Mechanisms of organophosphorus pesticide toxicity in the context of airway hyperreactivity and asthma. Am J Physiol Lung Cell Mol Physiol. 2018 Oct 1; 315(4): L485-L501, doi: 10.1152/ajplung.00211.2018

12. Karami-Mohajeri S, Abdollahi M. Toxic influence of organophosphate, carbamate, and organochlorine pesticides on cellular metabolism of lipids, proteins, and carbohydrates: a systematic review. Hum Exp Toxicol. 2011; 30(9): 1119-40.

13. Santus P, Corsico A, Solidoro P, Braido F, Di Marco F, Scichilone N Oxidative Stress and Respiratory System: Pharmacological and Clinical Reappraisal of N-Acetylcysteine. COPD. 2014; 11(6): 705-717.

14. Ohayo-Mitoko GJA, Kromhout H, Simwa JM, Boleij JSM, Heederik D. Self reported symptoms and inhibition of acetylcholinesterase activity among Kenyan agricultural workers. Occup Environ Med. 2000; 57: 195-200.

15. Ye M, Beach J, Martin JW, Senthilselvan A. Occupational pesticide exposures and respiratory healt. Int J Environ Res Public Health. 2013; 10(12): 6442-71.

16. Barczyk A, Sozańska E, Pierzchała W. The influence of occupational exposure to pesticides on the frequency of chronic obstructive pulmonary diseases. Wiad Lek. 2006; 59: 596-600. 
17. Rinsky JL, Richardson DB, Kreiss K, Nylander-French L, Beane Freeman LE, London SJ, Henneberger PK, Hoppin JA. Animal production, insecticide use and self-reported symptoms and diagnoses of COPD, including chronic bronchitis, in the Agricultural Health Study. Environ Int. 2019; 127: 764-772. https://doi.org/10.1016/j.envint.2019.02.049

18. Hoppin JA, Valcin M, Henneberger PK, Kullman GJ, Umbach DM, London SJ, et al. Pesticide use and chronic bronchitis among farmers in the agricultural health study. Amer J Ind Med. 2007; 50: 969-979.

19. Pesatori AC, Sontag JM, Lubin JH, Consonni D, Blair A. Cohort mortality and nested case-control study of lung cancer among structural pest control workers in Florida (United States). Cancer Cause Control. 1994; 5: 310-318.

20. Lee WJ, Blair A, Hoppin JA, Lubin JH, Rusiecki JA, Sandler DP, Dosemeci M, Alavanja Mc. Cancer incidence among pesticide applicators exposed to chlorpyrifos in the agricultural health study. J Natl Cancer Inst. 2004; 96: 1781-1789.

21. Freeman LEB, Bonner MR, Blair A, Hoppin JA, Sandler DP, Lubin JH, Dosemeci M, Lynch CF, Knott C, Alavanja MC. Cancer incidence among male pesticide applicators in the agricultural health study cohort exposed to diazinon. Amer J Epidemiol. 2005; 162: 1070-1079.

22. Rusiecki JA, Hou L, Lee WJ, Blair A, Dosemeci M, Lubin JH, Bonner M, Samanic C, Hoppin JA, Sandler DP, Alavanja MC. Cancer incidence among pesticide applicators exposed to metolachlor in the agricultural health study. Int J Cancer. 2006; 118: 3118-3123.

23. Hou L, Lee WJ, Rusiecki J, Hoppin JA, Blair A, Bonner MR, Lubin JH, Samanic C, Sandler DP, Dosemeci M, Alavanja MC. Pendimethalin exposure and cancer incidence among pesticide applicators. Epidemiology. 2006; 17: 302-307.

24. Bonner MR, Freeman LEB, Hoppin JA, Koutros S, Sandler DP, Lynch CF, Hines CJ, Thomas K, Blair A, Alavanja MCR. Occupational Exposure to Pesticides and the Incidence of Lung Cancer in the Agricultural Health Study. Environ Health Perspect. 2017; Apr 125(4): 544-551. doi: 10.1289/EHP456

25. Purdue MP, Hoppin JA, Blai A, Dosemeci M, Alavanja MC. Occupational exposure to organochlorine insecticides and cancer incidence in the agricultural health study. Int J Cancer. 2007; 120: 642-649.

26. Bonner MR, Lee WJ, Sandler DP, Hoppin JA, Dosemeci M, Alavanja $\mathrm{MC}$. Occupational exposure to carbofuran and the incidence of cancer in the agricultural health study. Environ Health Perspect. 2005; 113: 285-289.

27. Samanic C, Rusiecki J, Dosemeci M, Hou L, Hoppin JA, Sandler DP, Lubin J, Blair A, Alavanja MC. Cancer incidence among pesticide applicators exposed to dicamba in the agricultural health study. Environ Health Perspect. 2006; 114: 1521-1526.

28. Christensen CH, Platz EA, Andreotti G, Blair A, Hoppin JA, Koutros S, Lynch CF, San dler DP, Alavanja MC. Coumaphos exposure and incident cancer among male participants in the agricultural health study (AHS). Environ Health Perspect. 2010; 118: 92-96.

29. van Bemmel DM, Visvanathan K, Beane Freeman LE, Coble J, Hoppin JA, Alavanja MC. S-ethyl-N,N-dipropylthiocarbamate exposure and cancer incidence among male pesticide applicators in the agricultural health study: A prospective cohort. Environ Health Perspect. 2008; 116: 1541-1546.

30. Lynch SM, Mahajan R, Beane Freeman LE, Hoppin, JA, Alavanja MC. Cancer incidence among pesticide applicators exposed to butylate in the agricultural health study (AHS). Environ Res. 2009; 109: 860-868.

31. Lynch SM, Rusiecki JA, Blair A, Dosemeci M, Lubin J, Sandler D, Hoppin JA, Lynch CF, Alavanja MC. Cancer incidence among pesticide applicators exposed to cyanazine in the agricultural health study. Int J Environ Res Public Health 2013; 10: 6467.
32. Mahajan R, Blair A, Lynch CF, Schroeder P, Hoppin JA, Sandler DP, Alavanja MC. Fonofos exposure and cancer incidence in the agricultural health study. Environ Health Perspect. 2006; 114: 1838-1842.

33. Mahajan R, Bonner MR, Hoppin JA, Alavanja MC. Phorate exposure and incidence of cancer in the agricultural health study. Environ Health Perspect. 2006; 114: 1205-1209.

34. Koutros S, Mahajan R, Zheng T, Hoppin JA, Ma X, Lynch CF, Blair A, Alavanja MC. Dichlorvos exposure and human cancer risk: results from the agricultural health study. Cancer Cause Control. 2008; 19: 59-65.

35. Greenburg DL, Rusiecki J, Koutros S, Dosemeci M, Patel R, Hines CJ, Hoppin J, Alavanja MC. Cancer incidence among pesticide applicators exposed to captan in the Agricultural Health Study. Cancer Cause Control. 2008; 19: 1401-1407.

36. Zendehdel R, Tayefeh-Rahimian R, Kabir A. Chronic exposure to chlorophenol related compounds in the pesticide production workplace and lung cancer: a meta-analysis. Asian Pac J Cancer Prev. 2014; 15(13): 5149-53.

37. Atamas SP, Chapoval SP, Keegan AD. Cytokines in chronic respiratory diseases. F1000 Biol Rep. 2013; 5: 3.

38. De Jong K, Boezen MH, Kromhout H, Vermeulen R, Postma DS, Judith M. Association of Occupational Pesticide Exposure With Accelerated Longitudinal Decline in Lung Function. American Journal of Epidemiology. 2014; 179(11): 1323-1330. https://doi.org/10.1093/ aje/kwu053

39. Nerilo SB, Martins FA, Nerilo LB. Pesticide use and cholinesterase inhibition in small-scale agricul-tural workers in southern Brazil. Braz J Pharm Sci. 2014; 50: 783-91.

40. Ye M, Beach J, Martin JW, Senthilselvan A. Occupational pesticide exposures and respiratory healt. Int J Environ Res Public Health. 2013; 10(12): 6442-71.

41. Baur X, Budnik LT, Preisser AM. Health risks of residual fumigants in international transport containers. Dtsch Med Wochenschr. 2010; 135(11): 516-21. doi: 10.1055/s-0030-1249198. Epub 2010 Mar 10.

42. Newman LS, Rose CS, Bresnitz EA, Rossman MD, Barnard J, Frederick M, Terrin ML, Weinberger SE, Moller DR, McLennan G, Hunninghake G, DePalo L, Baughman RP, Iannuzzi MC, Judson MA, Knatterud GL, Thompson BW, Teirstein AS, Yeager H Jr, Johns CJ, Rabin DL, Rybicki BA, Cherniack R; ACCESS Research Group. A Case Control Etiologic Study of Sarcoidosis: Environmental and Occupational Risk Factors. Am J Respir Crit Care Med. 2004 Dec 15; 170(12): 1324-30. Epub 2004 Sep 3

43. Slager RE, Simpson SL, Levan TD, Poole JA, Sandler DP, Hoppin JA. Rhinitis associated with pesticide use among private pesticide applicators in the agricultural health study. J Toxicol Environ Health A. 2010; 73(20): 1382-93. doi: 10.1080/15287394.2010.497443

44. Hoppin JA, Umbach DM, Kullman GJ, Henneberger PK, London SJ, Alavanja MCR, Sandler DP. Pesticides and other agricultural factors associated with self-reported farmer's lung among farm residents in the Agricultural Health Study. Occup Environ Med. 2007; May 64(5): 334-342, doi: 10.1136/oem.2006.028480

45. Jalilian H, Neghab M, Tatar M, Taheri S. Respiratory and dermal symptoms and raised serum concentrations of biomarkers of oxidative stress among pesticide retailers. Int J Occup Environ Med. 2018; 9: 194-204.

46. Lekei EE, Ngowi AV, London L. Pesticide retailers' knowledge and handling practices in selected towns of Tanzania. Public Health. 2019; 174: 31-41. https://doi.org/10.1016/j.puhe.2019.05.024

47. Buralli RJ, Ribeiro H, Mauad T. Respiratory Condition of Family Farmers Exposed to Pesticides in the State of Rio de Janeiro, Brazil. Int J Environ Res Public Health. 2018; 15(6): 1203. 